\title{
ANALISIS PERANCANGAN PC (PERSONAL COMPUTER) ROUTER PROXY UNTUK MENGGABUNGKAN TIGA JALUR KONEKSI DI INDOSPEED
}

\author{
Bangun Harizal, Adnan Purwanto, Wahyu Pamungkas \\ Program Studi Diploma III Teknik Telekomunikasi Purwokerto \\ Bangun_harizal@yahoo.com
}

\begin{abstract}
ABSTRAKSI
Router sangat berperan penting dalam jaringan komputer. Kecepatan pengiriman juga dapat diatur oleh router. Untuk mendapatkan router dapat membeli sebuah produk router namun juga dapat merancang sendiri dengan menggunakan personal komputer. Mikrotik adalah salah satu produsen router yang menyediakan produk dalam bentuk hardware maupun software. Apabila ingin mengeluarkan biaya sedikit untuk merancang router dapat menggunakan operating system Ubuntu. Operating system ini bersifat open source dan disediakan secara gratis oleh produsennya. Bila ingin merancang router dengan OS ini dapat memanfaatkan personal komputer yang sering digunakan di rumah-rumah atau perkantoran. Penggabungan kinerja kedua jenis router ini juga bisa dimanfaatkan untuk menutupi kekurangan satu sama lain. Dengan adanya proxy dalam suatu jaringan lokal maka penggunaan bandwidth dapat dihemat. Karena ada beberapa cache website yang tersimpan didalamnya dan jika website yang sama diakses oleh pengguna lain, router hanya mentransmisikannya dari proxy ke komputer yang melakukan request.
\end{abstract}

Kata Kunci : Router, Ubuntu, PC Router, Proxy, Mikrotik, RB750.

\begin{abstract}
Router very important for computer network. To get the router can buy a router products but can also design your own using personal computers. Mikrotik is one of the router manufacturer that provides products in the form of hardware or software. If you want to payless to design a router can use operating system Ubuntu. This operating system is open source and provided free of charge by the manufacturer. If you want to design a routerwith this OScanmake use of personal computers are often used in homes or offices. Merging the performance of both types of routers can also be usedto cover the lack of one another. With the proxy on a local network then the use of bandwidth can be saved. Becausethere are several websites cached and stored therein if the same website is accessed by other users, the router transmits only from the proxy to the computerwhich make the request.
\end{abstract}

Keywords: Router, Ubuntu, PC Router, Proxy, Mikrotik, RB750.

\section{PENDAHULUAN}

\section{Latar Belakang}

Internet merupakan kumpulan dari jutaan komputer dari seluruh pelosok dunia yang saling terhubung untuk saling memberikan informasi selama $24 \mathrm{jam}$. Internet memberikan pengaruh yang besar tehadap dunia komunikasi dan komputer. Komputer ini bisa terdapat dalam rumah, sekolah, kantor, departemen pemerintahan, universitas dan lainlain.

Internet berawal dari sebuah pemikiran Advanced Researech Projects Agency (ARPA), sebuah agensi Departement of Deence (DoD) AS yang mensponsori pengembangan suit protokol TCP/ IP. ARPA kemudian berganti nama memjadi Defence Advanced Research Project Agenc (DARPA) yang bekerjasama dengan lembaga pendidikan dan institusi riset untuk mengembangkan teknologi komunikasi protokol yang dikenal dengan nama "the Internetting project" dan "the system of networks" yang kemudian dikenal dengan "Internet".

Pengembangan internet dilakukan secara terus menerus hingga banyak partisipan dari seluruh penjuru dunia yang terlibat. Sampai sekarang jumlah pengguna internet terus bertambah seiring dengan perkembangannya. Karena banyaknya 
kelompok maupun perorangan yang terlibat, manfaat internet menjadi sangat penting dan menjadi kebutuhan sehari - hari. Melalui internet orang - orang dapat saling bertukar informasi, berkomunikasi, dan bertransaksi. Para pengusaha juga bisa mengembangkan usahanya dengan internet.

Salah satu usaha yang menggunakan jasa internet adalah warnet (warung internet) yang menyediakan jasa kepada orang - orang yang tidak mempunyai koneksi internet sendiri di rumah. Setiap warnet memiliki jumlah komputer client yang tidak sedikit sehingga memerlukan bandwidth yang cukup besar untuk memenuhi kebutuhan internet setiap komputer. Tidak hanya bandwidth yang besar, diperlukan juga router untuk mengatur kecepatan koneksitas tiap komputer. Router adalah sebuah alat jaringan komputer yang mengirimkan paket data melalui sebuah jaringan atau internet menuju tujuannya, melalui sebuah proses yang dikenal sebagai routing. Di warnet router berfungsi sebagai gerbang penghubung antara jaringan local area network yang terdapat di warnet dengan jaringan yang lain. Cara kerja router mirip dengan bridge jaringan, yakni mereka dapat meneruskan paket data jaringan dan dapat juga membagi jaringan menjadi beberapa segmen atau menyatukan segmen-segmen jaringan. Router juga dapat difungsikan sebagai proxy untuk menghemat penggunaan bandwidth.

Warnet tidak akan berjalan usahanya tanpa adanya Internet Service Provider (ISP) yang menyediakan koneksi Internet. Bandwith koneksi dari ISP inilah yang nantinya akan dibagi ke tiap komputer di warnet. Namun terkadang menu paket data yang diberikan oleh ISP kurang mencukupi, sehingga membuat para pemilik warnet mengambil dua menu paket data bahkan lebih untuk memenuhi kebutuhan bandwith.

Warnet yang memiliki jumlah komputer yang banyak seperti di Indospeed memerlukan lebar bandwidth yang besar. Namun, menu yang disediakan oleh ISP kurang menyukupi kebutuhan sehingga diperlukan untuk mengambil dua menu paket yang disediakan oleh speedy. Kemudian sebagai backup konkesi jika sewaktu - waktu speedy down Indospeed menggunakan jasa koneksi dari Mentari Satria. Ketiga jalur koneksi tersebut digabungkan ke dalam sebuah router proxy dan bagi - bagi lagi ke komputer jalam jaringan LAN warnet.

Perbedaan antara penelitian ini dengan penelitian sebelumnya yang pernah dibuat adalah penelitian sebelumnya memiliki konsep router sebagai berikut:

1. Menggunakan PC yang digunakan sebagai router.

2. Menggunakan mikrotik OS.

3. Menggabungkan dua koneksi.

4. Koneksi yang digabungkan yaitu Speedy (384 Kbps) dan Jardiknas (512 Kbps).

Sedangkan konsep router pada penelitian ini adalah

1. Menggunakan sistem dual load balancing mikrotik OS dan UBUNTU server.

2. Mikrotik $O S$ dalam bentuk router board dan UBUNTU server OS berupa PC router.

3. Koneksi yang digabungkan adalah dua line speedy (3Mbps dan 2Mbps) dan Mentari (314Kbps)

4. Penggabungan dua line speedy menggunakan routerboard mikrotik dan mentari dihubungkan pada router PC.

Pada penelitian sebelumnya router Mikrotik bertugas sebagai load balancing (LB) yaitu membagi beban trafik secara seimbang ke line koneksi, tujuannya agar trafik dapat berjalan optimal, memaksimalkan throughput, memperkecil waktu tanggap, dan menghindari overload pada salah satu jalur koneksi. Dial PPPoE di lakukan pada modem ADSL sehingga koneksi dari modem sudah menggunakan IP lokal. Koneksi dari jardiknas juga sudah berupa IP, sehingga line speedy dan jardiknas dapat di load balancing pada router mikrotik.

Pada penelitian ini load balancing dua jalur speedy dan mentari dilakukan terpisah. Load balancing antara speedy 2 Mbps dan $3 \mathrm{Mbps}$ dilakukan pada router mikrotik kemudian koneksi dari mentari digabungkan pada router ubuntu server. Cara ini dilakukan terpisah karena dial line speedy dilakukan pada router Mikrotik, jadi modem ADSL hanya digunakan dalam mode bridge dan koneksi dari mentari sudah berupa IP. Jika dial PPPoE 
dilakukan pada modem maka router Mikrotik tersebut tidak dapat diatur melalui telnet sehingga menyulitkan jika terjadi trouble untuk seorang admin dalam melakukan troubleshooting dengan menggunakan router tersebut. Jika menggunakan telnet maka seorang admin bisa melakukan troubleshooting dengan menggunakan komputer lain bahkan dalam jaringan lokal lain yang terhubung dengan internet.

Kelebihan Mikrotik adalah mudah dalam melakukan setting load balancing, jika terjadi disconnect maka proses auto connect lebih cepat. Kelemahannya adalah load balancing pada Mikrotik tidak mengenal Domain Name System (DNS), fitur-fiturnya berlisensi sehingga tidak dapat digunakan secara gratis. Sedangkan UBUNTU kebalikan dari Mikrotik selain itu juga semua tool yang digunakan didapatkan secara gratis dan dapat diatur lebih rinci sesuai dengan keinginan administrator.

Atas dasar tersebut, maka topik kajian ini berjudul "ANALISIS PERANCANGAN PC (PERSONAL COMPUTER) ROUTER PROXY UNTUK MENGGABUNGKAN TIGA JALUR KONEKSI DI INDOSPEED”. Sedangkan tujuan kajian ini adalah menganalisis proses perancangan router proxy untuk menggabungkan tiga jalur koneksi di Indospeed supaya bisa digunakan untuk mengatur kecepatan data tiap IP.

\section{Tujuan}

Tujuan penulisan ini adalah:

1. Mengetahui bagaimana caranya membuat router proxy dan menggabungkan dua line koneksi.

2. Mengetahui cara memindahkan koneksi jika salah satu koneksi dari ISP sedang mengalami disconnect.

Mengatur kecepatan tiap komputer

\section{Identifikasi Masalah}

Dari penjelasan diatas maka terdapat beberapa permasalahan yang di ketahui yaitu:

1. Bagaimana cara menghubungkan tiga jalur koneksi ke routerboard Mikrotik dan PC router Ubuntu?
2. Bagaimana cara melakukan load balancing terhadap dua jalur koneksi dari Speedy?

3. Bagaimana cara konfigurasi proxy PC router Ubuntu?

4. Bagaimana cara membatasi kecepatan koneksi yang diterima oleh user?

Bagaimana cara memindahkan koneksi jika line dari salah satu ISP sedang down?

\section{Metode Penelitian}

Metode penelitian yang digunakan dalam penelitian ini adalah :

1) Instrumen Penelitian

Penelitian ini memerlukan sebuah personal komputer, router board Mikrotik, operating system Ubuntu server 10.04, Hub, dua buah modem Asymmetric Digital Subscriber Line (ADSL), kabel twisted pair, dan konektor RG 45.

2) Variabel Penelitian

Sistem operasi yang digunakan untuk membuat PC router proxy adalah Ubuntu server sehingga variabel yang akan dibahas merupakan cara merancang PC tersebut supaya dapat difungsikan sebagai proxy server. Jalur koneksi yang digunakan terdapat tiga jalur yang akan dibagi ke 45 PC client. Supaya semua client mendapatkan bandwidth maka setiap client harus diatur maksimal bandwidth yang digunakan. Cara menguji hasil pembagian banwidth yaitu dengan mengukur parameter kecepatan akses HTTP untuk 45 client. Selain itu jika salah satu jalur koneksi sedang putus maka router mengalihkan trafik ke jalur koneksi yang bisa dipakai.

3) Metode pengumpulan data

Penulis berusaha mencari bahan - bahan dari berbagai literature yang berkaitan tentang router, Ubuntu, dan cara penggabungan beberapa line koneksi. Serta melakukan wawancara dengan narasumber yang memahami tentang konsep routing untuk melengkapi datadata yang diperlukan dalam analisa. 


\section{DASAR TEORI}

\section{Jaringan komputer}

Jaringan merupakan kumpulan dari beberapa titik yang saling terhubung dan saling berkomunikasi. Media penghubung antar titik ini merupakan media transmisi yang dapat mengirimkan data dari satu titik ke titik yang lain.

Jaringan komputer merupakan kumpulan beberapa komputer dan alat-alat lain yang dihubungkan dengan suatu media untuk saling berkomunikasi satu sama lain. Media penghubung dalam jaringan komputer dapat menggunakan kabel atau non kabel. Jaringan komputer yang menggunakan media kabel sebagai penghubungnya, biasanya menggunakan jenis kabel twisted pair, kabel coaxial, dan kabel serat optik. Sedangkan jaringan komputer yang menggunakan media non kabel sebagai penghubungnya memanfaatkan gelombang radio elektromagnetik untuk mengirim dan menerima data.

\section{Macam-macam Jaringan Komputer}

Ada beberapa macam jaringan komputer berdasarkan area diantaranya adalah:
a. Local Area Network (LAN)
b. Metropolitan Area Network (MAN)
c. Wide Area Network (WAN)
d. Jaringan Internet

\section{Komponen Hardware Jaringan Komputer}

Hardware jaringan komputer adalah seperangkat komponen yang dibutuhkan sebagai syarat untuk membangun sebuah jaringan komputer. Secara umum, komponen hardware yang dibutuhkan seperti:

1. Server

2. Workstation

3. Network Interface Card (NIC)

4. Media komunikasi

5. Konektor

6. Peralatan tambahan $(\mathrm{Hub})$

\section{Router}

Router adalah sebuah alat jaringan komputer yang mengirimkan paket data melalui sebuah jaringan atau internet menuju tujuannya melalui sebuah proses yang dikenal sebagai routing. Di dalam warnet router berfungsi sebagai gerbang penghubung antara jaringan local area network yang terdapat di warnet dengan jaringan yang lain. Cara kerja router mirip dengan bridge jaringan, yakni mereka dapat meneruskan paket data jaringan dan dapat juga membagi jaringan menjadi beberapa segmen atau menyatukan segmen-segmen jaringan.

\section{Routing}

Routing adalah inti dari seluruh sistem kontrol jaringan, dalam hubungannya dengan komponen admission control, flow control, congestion control, untuk menentukan seluruh performansi jaringan dan kualitas serta kuantitas layanan pengiriman. Proses routing merupakan prinsip kerja layer network pada model OSI. Istilah routing digunakan untuk proses pengambilan sebuah paket dari sebuah alat dan mengirimkannya melalui network ke alat lain di sebuah network yang berbeda.

\section{IP Address}

Transmission Contro Protocol/Internet Protocol (TCP/IP) adalah alamat host dalam jaringan yang dibuat oleh Departement of Defence (DoD) supaya komunikasi berjalan lancar. TCP/IP pada model DoD tidak seperti model OSI, hanya terdiri dari empat layer yaitu layer process/application, layer Host-to-Host, layer internet, layer network access.

\section{HYPERTEXT TRANSFER PROTOCOL (HTTP).}

Aplikasi HTTP adalah standar mekanisme dalam mengakses data pada sebuah website. Data yang ditransfer bisa dalam bentuk plaintext, hypertext, audio, video. Tetapi HTTP lebih efektif jika digunakan untuk mentransfer data hypertext. Sistem pengiriman data pada HTTP sama seperti saat mengakses FTP dan SMTP yaitu client mengirimkan request ke server lalu server akan merespon (response) permintaan dari client dan mengirimkannya ke client.

\section{Sistem Operasi}

Sistem operasi merupakan suatu perangkat lunak yang digunakan sebagai dasar pada suatu sistem untuk mengontrol dan memanajemen perangkat keras. Terdapat beberapa sistem operasi yang digunakan 
untuk router seperti Mikrotik, Ubuntu, Clark connect, Pfsense, Smoothwall, Vyatta, Unix, Freebsd, Openbsd, netbsd dan lain-lain.

\section{KONFIGURASI}

\section{Konfigurasi Mikrotik}

Konfigurasi Mikrotik yang digunakan untuk load balancing adalah melakukan konfigurasi pada IP address, setting dial out modem, pengaturan firewall dan pengaturan route.

\section{Konfigurasi Ubuntu}

Perancangan sebuah router Ubuntu diperlukan spesifikasi personal computer sebagai berikut :
a. PC dengan spesifikasi
a) Processor AMD Athlon II
b) RAM 1GB
c) Hardisk $250 \mathrm{~GB}$
b. DVD RW
c. CD ubuntu server 10.04
d. Dua buah LAN Ethernet PCI
e. Kabel Twisted pair
Pengaturan yang diperlukan dalam membangun sebuah $\mathrm{PC}$ router proxy adalah sebagai berikut:
a. Pengaturan IP address untuk tiap ethernet.
b. Pengaturan firewall.
c. Pengaturan gateway.
d. Pengaturan kecepatan akses untuk tiap user.
e. Pengaturan proxy
f. Pengaturan jalur koneksi.

\section{Konfigurasi komputer client / user}

Pengaturan yang dilakukan pada komputer client adalah pengaturan IP address, gateway dan domain name system.

\section{ANALISA}

\section{Analisa Mikrotik}

Analisa proses load balancing dilakukan denga melihat melaihat penggunaan total trafik terhadap pembagian trafik ke dalam dua jalur koneksi. Jika beban trafik telah terbagi secara seimbang maka konfigurasi load balancing telah berhasil. Pembagian beban trafik juga dapat dilihat pada connection list pada firewall.

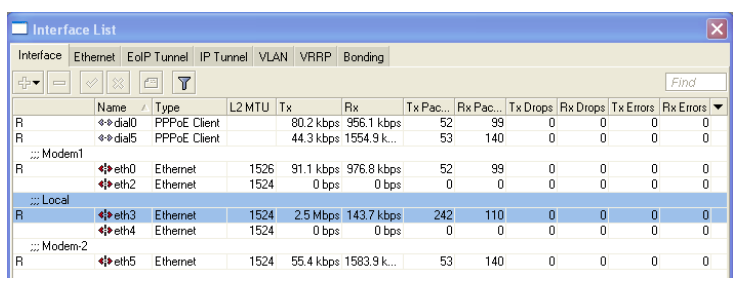

Gambar 1 : Interface list

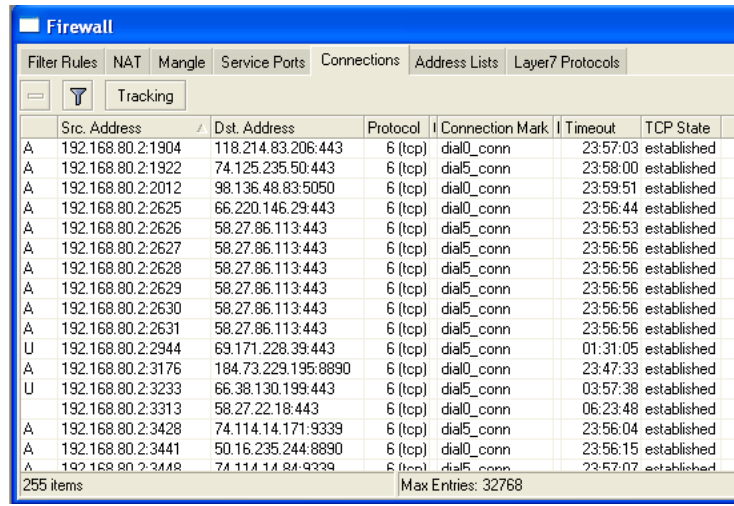

Gambar 2 : connection list pada firewall

\section{Analisa PC router Ubuntu}

Analisa pada PC router Ubuntu dengan melakukan tes koneksi ke internet. Tes koneksi dilakukan dengan melakukan ping ke www.google.com. Kemudian analisa selanjutnya adalah melihat $\log$ proxy. Jika list pada log proxy berjalan maka fungsi proxy pada PC router tersebut sudah bekerja.

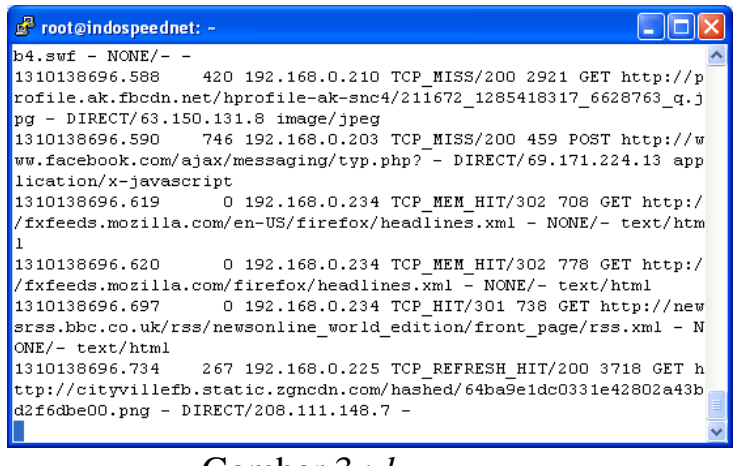

Gambar $3: \log$ proxy

Untuk memeriksa bahwa fungsi router pada PC router ini berhasil dapat dilihat dengan melakukan perintah "iftop $-i$ eth $3-P$ $-n$ ". Jika tampilan sudah menunjukkan beberapa trafik yang dipakai oleh client maka fungsi router untuk melewatkan paket sudah berjalan. 


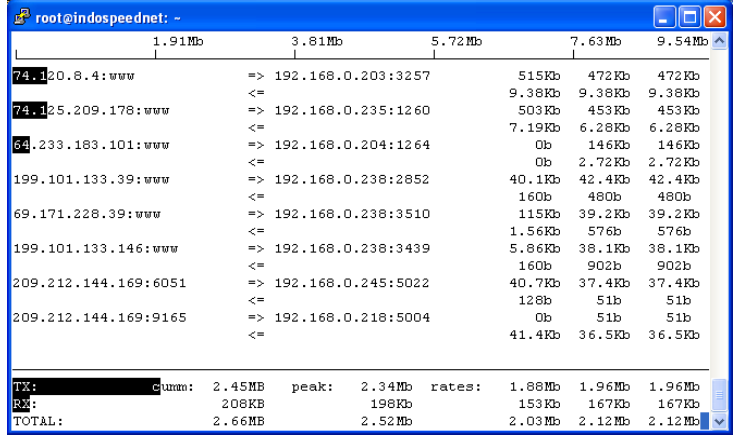

Gambar 4 : Trafik pada eth3

\section{KESIMPULAN}

1. Load balancing adalah proses pendistribusian koneksi supaya penggunaan jalur koneksi seimbang.

2. Pembagian jalur didasarkan atas alamat tujuan (destination address)

3. Proxy pada Ubuntu server dapat di konfigurasi menggunakan squid.

4. Pengarahan trafik ke proxy dapat dikonfigurasi pada PC router Ubuntu.

5. Proses maintenance terhadap proxy sangat diperlukan supaya kinerjanya tetap optimal.

\section{DAFTAR PUSTAKA}

[1] Annonymous.

2010.

http://raraluvvand-

pengetahuanku.blogspot.com/2010/02/ jenis-jenis-konektor-fiber-optic.html. 15 Desember 2010. 9.30 WIB.

[2] Annonymous.

2010. http://www.rezitatkj2.co.cc/2009 110 1 archive.html. 15 Desember 2010. 9.34 WIB.

[3] Annonymous. 2010. http://www.afsoncable.com/productsRG58-Low-loss--50-Ohm-Coaxial-

Cable-97.html. diakses pada 14 Desember 2010. 12.14 WIB.

[4] Annonymous. 2010. http://www.sanyuancable.com/rg6cable.htm. diakses pada 14 Desember 2010. 12.11 WIB.

[5] Annonymous. 2010. Network File System.

https://help.ubuntu.com/8.04/servergui
de/C/network-file-system.html. diakses pada 24 November 2010. 22.02 WIB.

[6] Annonymous. 2010. Linux untuk Umat Manusia. http://www.ubuntu.or.id/. diakses pada 3-12-2010. 2.52 WIB.

[7] Annonymous. $2010 . \quad R J-45$. http://www.nullmodem.com/RJ45.htm. diakses pada 30 November 2010. 11.00 WIB

[8] Annonymous. 2010. sejarah Internet. http://www.scribd.com/doc/4550234/s ejarah-internet. diakses pada tanggal 2 November 2010. 14.32 WIB.

[9] Annonymous. 2010. http://www.socnb.com/techbox/hprodu ct_e/opto.html. diakses pada 14 Desember 2010. 14.53 WIB.

[10] Citraweb. 2005-2011. Mangle. http://www.mikrotik.com/testdocs/ros/ 3.0/qos/mangle.php. Diakses pada 1604-2011 08.15 WIB.

[11] Citraweb. 2005-2011. Router RB750. http://mikrotik.co.id/produk_lihat.php? $\underline{\mathrm{id}=194}$. Diakses pada 30-4-2011. 09.00 WIB.

[12] Herlambang, Moch., Linto, \& L., Aziz, Catur. 2008. Panduan Lengkap Menguasai Router Masa Depan menggunakan Mikrotik RouterOS ${ }^{T M}$. Yogyakarta. ANDI.

[13] Kadir, Abdul. 2002. Pengenalan UNIX dan LINUX. Yogyakarta. Andi.

[14] Klensin, J. 2008. Simpel Mail Transfer Protoco.

http://tools.ietf.org/html/rfc5321\#secti on-1.1. diakses pada 25 november 2010. 11.46 WIB.

[15] Kristanto, Andri. 2003. JARINGAN KOMPUTER. Jakarta. Graha Ilmu.

[16] Lammle, Todd. 2004. CCNA Cisco Certified Network Associate Study Guide. Jakarta. PT Elex Media Komputindo

[17] McLaughlin, L. 1990. Line Printer Daemon Protocol. http://www.ietf.org/rfc/rfc1179.txt diakses pada 25 November 2010. 12.15 WIB. 